IRA-International Journal of Management \& Social Sciences

ISSN 2455-2267; Vol.04, Issue 02 (2016)

Pg. no. 455-463

Institute of Research Advances

http://research-advances.org/index.php/RAJMSS

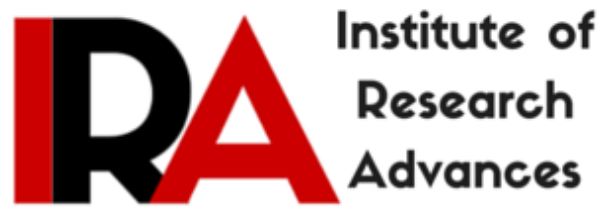

\title{
Psychographic Market segmentation of Junior College Students in Silchar, Assam
}

\author{
${ }^{1}$ Nilotpal Saha \\ Assistant Professor, Commerce College, \\ Kokrajhar BTAD, Assam, India.

\section{${ }^{2}$ Brajesh Kumar} \\ Assistant Professor, Assam University Silchar, \\ Assam, India.
}

Type of Review: Peer Reviewed.

DOI: http://dx.doi.org/10.21013/jmss.v4.n2.p15

\section{How to cite this paper:}

Saha, N., \& Kumar, B. (2016). Psychographic Market segmentation of Junior College Students in Silchar, Assam. IRA-International Journal of Management \& Social Sciences (ISSN 2455-2267), 4(2), 455-463. doi:http://dx.doi.org/10.21013/jmss.v4.n2.p15

(C) Institute of Research Advances

\section{(cc) BY-NC}

This work is licensed under a Creative Commons Attribution-Non Commercial 4.0 International License subject to proper citation to the publication source of the work.

Disclaimer: The scholarly papers as reviewed and published by the Institute of Research Advances (IRA) are the views and opinions of their respective authors and are not the views or opinions of the IRA. The IRA disclaims of any harm or loss caused due to the published content to any party. 


\section{ABSTRACT}

This paper discusses about characteristics of most enthusiastic buyers of a non-metro city. The paper adopts the analytical and exploratory research style based on primary data. It uses questionnaire based survey methods with a sample size of 250 junior college students (JCS) of Silchar, Assam, India. The paper tries to identify the segments depending upon the choices and purchasing decision made by these students on the basis of their psychographic profile.

The research is unique for academic and professional relevance. As the research on psychographic market segmentation in small city especially the city from North-Eastern Region called Silchar, Assam is very rare. Hence, this study may be regarded as masterpiece as it provides in-depth analysis on psychographic market segmentation, which is found to differ in several important aspects.

Keywords: Market segmentation, Psychographics, Junior College Students, Cluster analysis. Activities Interest and Opinion (AIO)

\section{Introduction}

The concept of market segmentation was first introduced by Smith, (1956). According to him market segmentation involved viewing heterogeneous market as a smaller number of homogenous markets, in response to differing preferences, attributable to the desire of consumers for more precise satisfaction to their varying wants. Thus a market segment consists of a group of customer who share a similar set of want (Kotlar).

It did not take a long time to become one of the much discussed concepts of marketing. Market segmentation is an essential element of marketing in industrialized countries and market segmentation research may be one of the richest areas in marketing science in terms of scientific advancement and development of methodology (Wedel \& Wansbeek, 1999). If properly applied marketing segmentation would guide companies in tailoring their product and service offerings to the groups which are most likely to purchase them. (Yenkelovich and Meer, 2006)

In order to identify market segment several approaches may be adopted. One of the most common ways of segmentation is through demographics, i.e., segmenting on the basis of variables like age, gender, education, income and other such characteristics of human beings. These variables are directly measurable and information regarding these variables can easily be collected from municipal or government registers.

\section{Psychographics}

The marketers soon understood the limitations of clustering people in terms of flat demographic data when the choice of consumption depends mostly on non-demographic terms. Kotler, in his book Marketing Management furnished an example of Ford Motor Company where the company designs Mustang automobile to appeal to young people who wanted inexpensive sports car. But it was found that many Mustangs were purchased by older buyers. It then realized that the target market is not chronologically young but the psychologically young. Such examples are abundant in marketing.

Meaningful segmentation depends on finding patterns of customer's actual buying behavior (Yenkelovich $\&$ Meer, 2006). Psychographic research primarily allows us to understand why consumers behave the way they do (Schiffman \& Kanuk, 2001). 
Demographic segmentation does provide information about the people who purchased a product, their age, gender, education, income and social status but neither answer why all people were buying same product nor does it go into what the motivation behind the showing same buying behavior. In order to understand customer psychographic information can put flash into demographic bones (Wells, 1975). Psychographic segmentation helps marketer understand buying behavior better and design communication programs through understanding lifestyle, interest, activities, opinion, personality, attitude, values.

Demby (1989) defines psychographics as "The use of psychological, sociological and anthropological factors, such as benefits desired (from behavior being studied), self-concept and lifestyle (or serving style) to determine how the market is segmented by the propensity of groups within the market - and their reasons- to make a particular decision about a product, person, ideology or otherwise hold an attitude or use a medium."

The article is structured in a logical and sequential manner, addressing the following aspects: Literature review, Study context, Methodology, Psychographic segmentation (Activities Interest and Opinion) and the final consideration

\section{Review of Literature}

The scholars and corporate throughout the world have conducted many surveys and investigations to understand and map the psychographic pattern of customers and its impact over the purchasing preferences. Study has been carried out to try and understand correlation between social class, income and buying behavior (Slocum \& Mathews, 1970); Social class and life style as predictor of shopping behavior (Rich \& Jain, 1968). Studies has also being carried out to understand importance of life status and consumer preference (Anderson 1984), and the importance of consumer behavior and cultural values (Henry 1976). There are also studies relating to the influence of the reference group on consumer brand purchase (Stafford 1966) and on the influence of the reference group on product and brand purchase (Beardon \& Etzel 1982). There are also studies like impact of role of sex on purchase decision (Qualls 1987) on working wives and expenditure on service (Bellanti \& Foster 1984). Identification, attitudinal and demographic questions frame nine lifestyle types to categorize American consumers (Mitchell, 1978). Other set of studies addressed to heterogeneity between senior citizen market (Day et al., 1987); and understanding the profile of the women in the USA, UK and France (Doughalas Urban, 1997).

Few prominent studies in the Indian context are: Interrelationship between religiosity, cast prejudices and conservatism lifestyle among four major faith groups: Hinduism, Islam, Sikh and Christianity. This Study was carried out in New Delhi (Kapoor, 1985); National Council of Applied Economic Research (NCAER) mapped ownership and purchasing patterns of consumer durable and non durable products and grouped Indian population into five major groups based on real disposable income and the ownership of the durables and consumption of non durable (Rao \& Natarajan, 1996); linkage between ownership of two wheelers and the behavior of their owners (Kapur, 1995); brand association of Denim brands with life style attributes by Adite Chatterjee in 1995 and understanding of changes in personality traits, family relationship, personal goals, and attitudes towards advertising and favored products among Indian consumers aged between 15-45 years by (Chatterjee,1996). Another study carried out to identify similar lifestyle segments based on classification of status symbol. The study surveyed 623 respondents in top four metropolitan centers in the country with at least one car in their disposal (Shirali\& Singh, 1997). Studies also conducted to understand psychographic profile of customers of newspapers in India (Anandan et al., 2006) and psychographic segmentation of Indian Urban customers (Kumar \&Sarkar, 2008). Paromita Goswami (2007) studied the effects of psychographics on the frequency of purchase of college goers of Kolkata. Seema Kapur (1995) studied the behavior of two wheeler owners and Adite Chatterjee (1995) studied lifestyle attributes of Denim brand users. Anil Kumar (2013) used psychographic tools to study the attitude of consumers towards durables. 
The above literature review illustrates that there is no study that examines the dynamics and contrast of psychographic details of youths in a fast growing town of North East India and about the youths those who are the future consumers and determining factors of future market.

\section{The Context: Silchar, Assam}

Silchar is the main town of Cachar District in the state of Assam in India. It is 343 kilometers south east of Guwahati city of Assam. It is the second-largest city of the state in terms of population and municipal area. Approximately 90\% residents of Silchar are Bengalis who speak the Sylheti dialect, There are also a number of who are Bihari, Bishnupriya Manipuri, Dimasa Kachari, Manipuri(meitei), Marwaris, Nepalies, Assamese and some tribal groups like Nagas form Nagaland, Mizos from Mizoram. Silchar is situated by the banks of the Barak River in what is popularly known as Barak Valley. Hence, due the presence of such variation within the population the research on psychographic market segmentation will be very affective.

\section{Research Gap \& Relevance of the Study}

The study shall show a picture of psychographic profile of the most enthusiastic buyers of a nonmetro city. The study results in segmenting non-metropolitan urban consumer into distinct behavioral groups. The main aim of the study is to identify the psychographic profile among the 'would be' targeted group identified in the study and their 'would be' buying behavior. No such study has been ever conducted in Silchar, Assam. This study is going to predict the future market and consumption habits of people of Silchar, Assam.

The study helps in understanding the lifestyle pattern of the youth of Silchar and the impact over marketing of product and services. The study shall try to examine the pattern and change of psychographic data of two different age and occupancy groups and shall try to explain how or why the transition takes place. This study, thus, shall help in future exploration of professional benefits in academic and commercial activities; beneficial to policy makers and corporate sector those willing to launch products at similar non metro cities.

Considering the importance of psychographic segmentation the present study covers the description of psychographic profile of Junior College Students (JCS) of Silchar.

\section{Methodology}

In order to fulfill the research objectives different survey and statistical tools has been used. To gather demographic information 9 questions were used, for better understanding of activities, interest and opinion an instrument of 26 questions each containing four options has been developed. For understanding values the standard LOV scale with 9 choices using ranking method, developed by Khel was adopted. In order to ascertain aspiration 26 dichotomous options were provided.

Primary data was collected using purposive sampling. The sample were collected from all the wards of Silchar in order to make sample more representative to population. The target JCS are actually part of a larger population of youth. 980 questionnaires were used for the larger survey covering total geographical area of Silchar. Any defect in questionnaire like responding multiple time in single answer, questionnaire with missing value and incomplete questionnaires were shorted and rejected at very beginning. Total of 684 questionnaire were finally accepted and data were entered into computer using SPSS package of IBM. Among this data 250 respondents were JCS who were studying in $11^{\text {th }}$ and $12^{\text {th }}$ standards in different colleges and schools.

In order to describe demographic characteristics standard statistical tools of counting, average and ratio were used. 
For segmentation combination of factor analysis, cluster analysis and canonical discernment analysis has been used. The following is the brief description: firstly we run Principle Component Analysis (PCA) with Verimax rotation. Which isolated 9 important factors which in combination described $49.89 \%$ of total variance. It had a Kaiser - Mayer Olkin (KMO) measure of sample adequacy .653 which is considered as mediocre as per guideline. The $\mathrm{z}$ scores of this 9 factors were considered for further analysis and clustering.

After this step k means clustering was run to identify the clusters and cluster solution with distance from cluster centroid were recorded from 2 group cluster to 10 group cluster.

Canonical discernment analysis were used in order to find suitable and meaningful cluster solution. This revealed that the 3 cluster solution is an ideal choice for explain the characteristic the sample.

Data for JCS were selected and narrated with crosstab and question wise observation of each groups separately.

\section{Research findings and nomenclature}

The psychographic market segmentation of JCS of Silchar, Assam consists of three segments. The segments are divided into three clusters they are Acquiescent, Traditionalist and Acquisitive. The table depicts the cluster wise division of the respondents belonging to the population sample of junior college of Silchar, Assam. The sizes of these segments are 88, 63 and 99 which covers 35.2\%, 25.2\% and 39.6\% respectably. To provide a visual approach of all three clusters and their distribution pattern figure 1 (in appendix) is drawn. The figure titled Canonical Discriminant Function of JCS of Silchar, Assam plots interpret three major clusters of the psychographic study. From the above graphical representation it can be said that the discriminant functions is to plot each group centroid in a two dimensional plot with one function against another function. The graph is shown by the two functions - Function 1 on the $\mathrm{X}$ axis and Function 2 on the $\mathrm{Y}$ axis and around the group centroids. The function reveals the factor loading of each variable on each discriminant function. It allows us to compare correlations and see how closely a group is related to each centroid. The figure 3.1 provides the canonical discriminant function with relevance to JCS of Silchar based upon the three major clusters. It is distinguishable that on function 2 the group one does not provide much variance and are mostly intermingled compared to other two groups. Whereas, the function 1 , shows the other two groups are scattered and hence reveals much behavioral differences.

Therefore, lets discuses the characteristics of each these clusters.

(a) Segment 1 (Acquiescent): The sample of this segment shows the following characteristics:-

- JCS of this segment are serious law abiders and conservatives. If, given a situation this group directly give the opinion that, they shall not support corruption and shall not pay bribe.

- This group is also strong conservative compared to other two segments of JCS. They are of opinion that girls are carrier of culture and so they should wear traditional dresses only.

- $\quad$ On the choice of mass communication this people are of the opinion that mass communication medium, like television are meant for total family and we should be selective to view channels.

- Majority of them believe that politics is essential and without a stable government peace and prosperity cannot be achieved and hence, one best party should be supported during election.

- $\quad$ This people make friends from all walks of life and friendlier than other two groups. Therefore they have broad social arena then other groups.

- $\quad$ This people are very career conscious as $62.5 \%$ said that they are ready to work at any place where opportunity is more. They are generally team workers and show high aspiration to lead others.

- $\quad$ This people are not much trend conscious, new changes in trends do not have much impact upon them. This group has the opinion that carrying a smart phone does not make any difference in their appearance.

- $\quad$ To them new fashion trends like tattoo has no practical use. 
- They wear formal dress suitable for the occasion and prefer clean and comfortable dress which may not be fashionable.

- This people show high degree of curiosity on work. Even they do not hesitate to open or break the machine in parts to know about technology working behind it. They collect things that they consider useful and try to make new useful and decorative things with them.

- $\quad$ They try to be self-sufficient and take help of others only if they face difficulty. They belief successful people take moderate risk and consider themselves as general person.

- $\quad$ This people are not so religious they are logical yet $69.3 \%$ believe that a fixed time for prayer is important, they try to think what is logical and just themselves they believe science cannot explain everything in his world. They read religious books but do not follow all the guidelines written within it.

- $\quad$ They consider money as most evil thing and there are many other approaches in life which are more important than money. This people are generally extroverted they stay mostly away in social gatherings and sometimes even avoid parities. They mostly prefer to stay alone at home and spend a quiet time alone.

- One of the major characteristics of this people is that they are travelers if they learn about an interesting place of natural beauty they shall try to visit this place at least once in their life.

- They are very particular about purchasing decision, as they prefix their opinion about what to purchase and know exactly what they need to purchase when they visit a shopping mall.

- This people show high aspiration to spend money for social causes and charity. They love to give gifts to their friends and spend money with family members. They prefer to save money rather than spending it in luxuries.

(b) Segment 2 (Traditionalist) One fourth of the sample (25.2\%) falls in this category which is mostly dominated by male gender. The sample population of this group shows following psychographic characteristics:

- $\quad$ They believe that movies and TV serials now a day's show more violence and sex and sensor board is allowing such thing which all family members cannot view together.

- Most of the members (69.9\%) of this segment admit that there is no harm in paying bribe to get things done without facing any social or legal obstacle and seems have no hesitation to do so.

- They consider that girls should not wear western dresses whereas; every girl should ware traditional dresses of their ethnicity just because girls are considered as carrier of culture.

- $\quad$ This people do not get involved into politics and when extremely necessary they support issue based politics and not any particular party.

- $\quad$ This people are choosy in selecting friends compared to other two groups, they choose friends from same age group, social class and economic status.

- $\quad$ This people are family oriented does not hesitate to change workplace to stay near family as for them family togetherness is utmost valuable.

- $\quad$ This people are generally not team workers, they favor comfortable environment and prefer to work alone compared to other two groups.

- $\quad$ This people are more fashionable and willing to boast while dressing and try to remain ready for photo shoot.

- They also welcome ultra-new trends in fashion like tattoo; as they consider that it fulfills modern fashion trends.

- $\quad$ They are also very enthusiastic about latest technology innovation and remain ahead to adopt them. They consider it is obsolete to carry old technology in this era of smart phone.

- Most of this people consider it worthless to enquire how does a machine work; they prefer to purchase products from market rather then make it at home.

- $\quad$ One of the major characteristics of this group is that if they find some useful material they store it for some time to resell them.

- $\quad$ They consider that lucky persons always become successful and those who take more risk ultimately become looser. They believe that some of their friends shall always remain luckier and more 
successful than them. They consider money as the most important thing in life and wealthy people are happier.

- This people are not so religious and consider that too much prayer is wastage of time. They believe that everything happening around us can be explained by science therefore they do not read books which are religious in nature and consider their own consciousness above holy books.

- $\quad$ This people try to follow a general lifestyle, they are more resistance to change and adopt new things, they also do not want to visit new place and only visit places if there is good communication and good numbers of people have already visited. This people try to become center of attraction of any gathering.

- $\quad$ This people are good shopper as they take more time in choosing goods, and consider the advice of salesmen They think, other consider their advice valuable for shopping decisions.

- $\quad$ Aspiration of this group revolves around fashion they shall purchase ornaments, gems and gold having latest design, cloths with trendy outlook and think to have tattoo.

- They shall spend for education of self and others; build home purchase land and car and household goods.

(c) Segment 3 (Acquisitive) - A good number of participants of this group are girls compared to other two groups. The sample of this segment shows the following characteristics:-

- $\quad$ This group generally belongs to higher income class. These people are less fashionable and are strong law abiders.

- People of this group consider mass media like television as an instrument for family entertainment.

- They consider that programs that come in television should meant for total family which we can view together. According to them family members should choose programmers according to their choice and believes that girls should wear dresses according to their own choice.

- $\quad$ They keep themselves informed about on-going political situations, but never get themselves involved. This people adhere law very seriously and hence, never pay bribe.

- $\quad$ This people are friendly and $85.9 \%$ says that they have friends from all walks of life.

- They are tough and very serious about career. They prefer to find out jobs near to their hometown and always are good team workers.

- $\quad$ This people are fun loving and thus generally do lots of enjoyment in social gatherings.

- $\quad$ This people prefer common type of dress \& do not follow fashion trends very quickly. On the contrary they love to get compliments how they are looking.

- A good number of people in this group consider tattoo as nasty, other consider of some kind of useless fashion trend. In short they avoid very strong and progressive fashion trend.

- This people show much curiosity on how a particular technology works and if they get chance they shall open available small working engines.

- Generally this people do-not keep decorative items for future. They prefer to throw them considering as junks.

- If something thing or service can be procured by money they do-not hesitate to avail that and generally refrain from trying to make that.

- $\quad$ This people are risk taker, hopeful for future and consider they are luckier.

- $\quad$ This people are god believer, they consider that a fixed time for prayer every day is very useful for both health and mental concentration.

- They consider that whatever is written in holy books are god own words and it is best to follow them.

- $\quad$ They consider that there are many things in this world which cannot be explained by science.

- They also consider that there are many things more important than money. i,e they consider money cannot purchase happiness. 
- This people love to travel but avoid adventure, they shall visit places only road and rail connectivity is good. Otherwise shall remain satisfied by seeing photos only. This people take opinion of their friends and family members for almost all purchases.

- $\quad$ This people consider spending money is worth if spend for fulfilling hobby, for luxury trips, for spending time with loved once and family members and spending for own education and save for future.

Finally, from the above illustrated method and description of psychographic market segmentation, helps to understand the ongoing life style within the Silchar town.

\section{Conclusion}

The paper examines the importance of psychographic study with the help of the selected sample from population. The present paper provides a measuring method of life style of Silchar people based upon Activities, Interests and Opinions (AIOs). Since selected group of sample is more homogeneous in nature the study reveals precise information regarding personality traits or existing values. The paper also confirms the linkage of purchasing behavior with psychological level of common people of the present context. From the statistical tests conducted it has been found that three major clusters are existing and where the marketers can develop segment-by-segment invasion plans and choose target market in a socially responsible way.

\section{Reference}

1. Anandan, C., Ravi, K. \& Mohan Raj, M. P. (2006, January).

2. Anderson, A. R., (1984). Life status changes and changes in consumer preferences and satisfaction. Journal of Consumer Research, 11, 184-190.

3. Beardon, W. C., \&Etzel, M. J., (1982). Reference group influence on product and brand purchase decisions. Journal of Consumer Research, 9, 183-194.

4. Bellanti, D., \& Foster, A.C., (1984). Working wives and expenditure on service. Journal of Consumer Research, 11, 700-710.

5. Chatterjee, A., (1996). Marketing to new Indian consumer of generation - I. Business Today.

6. Chatterjee, A., 1995. Personality ploy. Business Today.

7. Demby, E.H. (1994) Psychographics Revisited: The birth of a technique, Marketing Research Spring, 6(2), 26- 30.

8. Day, E., Davis, B., Dove, R., \& French, W., (1987). Reaching the senior citizen market(s). Journal of Advertising Research, 27, 23-30.

9. Doughlas, S. P., \& Urban, C.D., (1997). Lifestyle analysis to profile international markets. Journal of Marketing, 41, 46-53.

10. Goswami, P (2007) Psychographic Segmentation of College Goers of Kolkata, IIMB Management Review, March, 41-51.

11. Henry, W.A., (1976). Cultural values do correlate with consumer behaviour. Journal of Marketing Research, 13, 12-17.

12. Kotler, P. \& Keller, K. L. Marketing Management (12th ed.) New Jersey, USA, Pearson.

13. Kapoor, D., (1985). Religiosity, Caste Prejudice, Conservatism and Lifestyles in Four Faith Groups : A Psychometric Study. University of Delhi, India, Department of Psychology.

14. Kumar, A.N \& Joeseph, J.(2013) A study on the psychographics on Consumer Purchase Behavior: Attitudes towards Durables with Specific Relevance to Kochi Metro., International Journal of Business and Management Tomorrow, 3(4), 1-19. Retrieved from www. Ijbmt.com.

15. Kumar, V. R., Sarkar, A. (2008, May) Psychographic segmentation of Indian Urban Consumer. Journal of Asia Pacific Economy, 204-226.

16. Kapur, S. (1995) Lifestyle on Two Wheels, Business World.

17. Mitchell, A., (1984). The Nine American Lifestyles. New York: Warner Books. 
18. Qualls, W.J., (1987). Household decision behavior : the impact of husband and wife sex role orientation. Journal of Consumer Research, 14, 264-277.

19. Rich, S.U., \& Jain, S.C., (1968). Social class as predictors of shopping behaviour. Journal of Marketing Research, 5, 41-50.

20. Rao, S. L., \& Natarajan, I., (1996). Indian Market Demographics - The Consumer Classes. National Council for Applied Economic Research (NCAER).

21. Smith, W (1956) Product Differentiation and Marketing Segmentation as Alternative Marketing Strategies, Journal of Marketing, 21, 3-8.

22. Schiffman, L.G. \& Kanuk, L. L (2000). Consumer Behaviour. 7th ed. London.

23. Shirali, A., \& Singh, I., (1997). Status symbols: an A\&M ORG-MARG survey. Advertising and Marketing.

24. Stafford, J.E., (1966). Effects of group influence on consumer brand preference. Journal of Marketing Research, 3, 68-75.

25. Slocum, J.W., \& Mathews, H.L., (1969). Social class and commercial bank credit card usage. Journal of Marketing, 33, 71-78.

26. Wedel, M \& Wansbeek, T (1999) Marketing and econometrics: Editors' Introduction, Journal of Econometrics, 89 (1999), 1-14

27. Wells, W. D. (1975) Psychographics: A Critical Review. Journal of Marketing Research, XII, 196-213.

28. Yankelovich, D. \& Meer, D. (2006) Rediscovering Market Segmentation. Harvard Business Review, Feb 2006.

\section{Funding}

This research has been partially funded by University Grants Commission (UGC) of India. Under The scheme of Minor Research Projects of UGC NERO.

Figure 1: Canonical Discriminant Function of JCS of Silchar, Assam

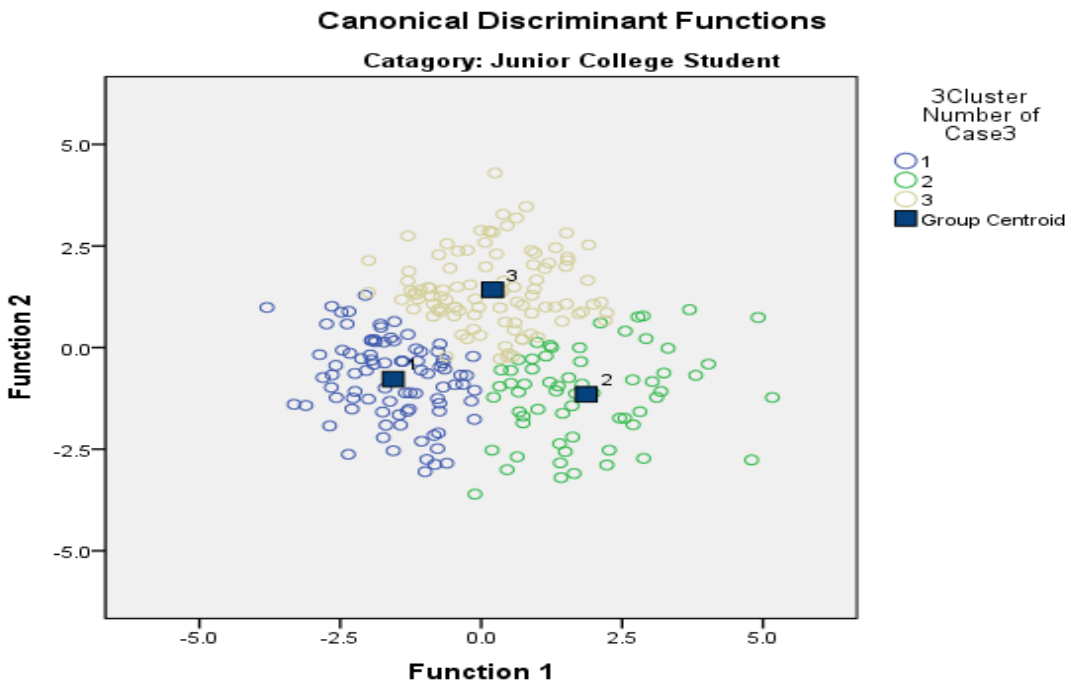

